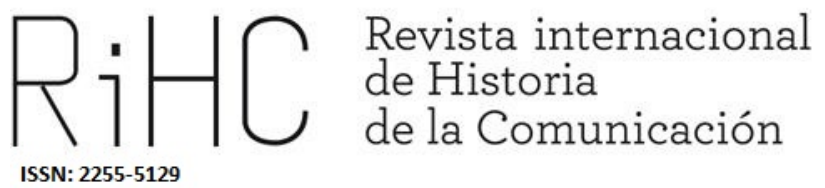

\title{
LA PRENSA PERIÓDICA Y EL NUEVO PRESIDENTE: LOS EDITORIALES DE LA NACIÓN ARGENTINA, LA TRIBUNA Y EL NACIONAL A FINES DE $1868^{1}$
}

The periodical press and the new President: the editorials of La Nación Argentina, La Tribuna and El Nacional at the end of 1868

DOI: http://dx.doi.org/10.12795/RiHC.2018.i10.11

Recibido: $30 / 04 / 2018$

Aceptado: $29 / 05 / 2018$

Publicado: 25/06/2018

Luis Sujatovich (D) https://orcid.org/0000-0003-1537-2942

Universidad Nacional de Quilmes (Argentina), sujatovich@gmail.com

Resumen: El artículo analiza los editoriales de La Nación Argentina, El Nacional y La Tribuna, entre octubre y diciembre de 1868, para comparar de qué manera se expresó

\footnotetext{
${ }^{1}$ El presente trabajo se enmarca en el Proyecto de Investigación "La Presidencia de D.F. Sarmiento (1868-1874) a través del análisis de tres diarios porteños: La Tribuna, El Nacional y La Nación.", desarrollado en el Departamento de Ciencias Sociales de la Universidad Nacional de Quilmes y financiado por una beca posdoctoral de CONICET (2016-2018).
} 
cada diario acerca del ascenso del nuevo Presidente Samiento. A partir del empleo de categorías lingüísticas se examinan sus discursos institucionales para reconocer sus particularidades y sus semejanzas en relación a las temáticas y modalidades elegidas. Además se examina en las formas discursivas empleadas por los medios gráficos para referirse a sus enunciadores (positivos y negativos) y para conformar su pacto de lectura con sus alocutarios.

Palabras clave: D.F. Sarmiento. Presidente. La Tribuna. El Nacional. La Nación Argentina.

Abstract: The article analyzes the editorials of La Nación Argentina, El Nacional and La Tribuna, between October and December of 1868, to compare how each diary was expressed about the rise of the new President Sarmiento. Starting from the use of linguistic categories are examined his speeches and institutional arrangements for recognizing their particularities and their similarities in relation to the topics and modalities

chosen.

Keywords: D.F. Sarmiento. President. The Tribune. The National. The Argentine Nation.

\section{Introducción}

La asunción a la presidencia de Domingo Faustino Sarmiento significó un hecho relevante para el naciente Estado nación: por primera vez las autoridades salientes pudieron entregar los atributos de mando en una ceremonia ajustada a las normas cívicas (Bargoni, Míguez, 2010; Campobassi, 1975; Rebollo Paz, 1968). También es preciso consignar otra particularidad: su origen sanjuanino y su escaso arraigo con las fuerzas políticas de la ciudad de Buenos Aires. Esta doble condición negativa no fue óbice, sin embargo, para su triunfo en las elecciones. Pero ¿qué sucedió para que en apenas seis años se hayan modificado las condiciones políticas partidarias que permitieron su ascenso al poder? Se pueden mencionar -al menos- dos acontecimientos que resultan significativos. El primero de ellos estuvo relacionado con las relaciones que fueron forjando la joven oficialidad del ejército en la Guerra del Paraguay, pues allí comenzaron los trabajos electorales, a partir de la buena relación entre ellos y Sarmiento. Además, la división de los porteños entre nacionalistas (cuyo mayor exponente era B. Mitre) y autonomistas (liderado por A. Alsina) debilitó a las fuerzas de la provincia. Y si B. Mitre, desde la presidencia pudo construir lazos partidarios con oligarquías de algunas provincias (en ciertos casos empleando la fuerza del ejército de línea) que le permitieron posicionarse como una facción hegemónica, los autonomistas debieron seguir la misma táctica, aunque sin los recursos económicos ni de coerción con que contaba B. Mitre. Sin embargo, esta disputa al interior de 
Buenos Aires, propició el ingreso de nuevos actores políticos a las contiendas electorales.

La particular configuración política electoral sobre la que se cimentó la candidatura de D.F. Sarmiento es resumida por Lettieri (2008: 40), de la siguiente forma:

Un grupo de jóvenes oficiales del Ejército Nacional asumió la iniciativa de lanzar la candidatura presidencial, por el período 1868-1874, de Domingo F. Sarmiento (...) Como resultado de largas y complejas negociaciones la propuesta fue adoptada por una original alianza, compuesta por el alsinismo, un grupo significativo de comandantes del Ejército Nacional, y un conjunto amorfo de fuerzas políticas del interior.

Es por ello que resulta significativo abordar el estudio de la prensa periódica en los inicios de la presidencia de D.F. Sarmiento. Pues el fortalecimiento del Estado nacional, a partir de la obra de su gobierno, también tuvo su correlato en el desarrollo de la prensa decimonónica.

No sería aventurado afirmar que tanto el periodismo como la política nacieron bajo el impulso del Estado (De Marco, 2006; Checa Godoy, 1993; Halperín Donghi, 1985), aun cuando aquél no consistiera más que en una entelequia perteneciente a un selecto grupo de patriotas. El desarrollo de ambos, y en consecuencia del Estado, estuvo ligado a los cambios y frustraciones que los dirigentes padecieron en sus mandatos 0 en sus intentos por acceder a él. Aunque la primera mitad del siglo XIX se caracterizó por las disputas fratricidas y los intentos por encontrar una forma moderna de la prensa que no se ajustara sólo a las necesidades ideológicas que le dieron origen, es posible encontrar algunas intenciones que permitieron imaginar una forma discursiva diferente dentro de un marco político y cultural más ligado a prácticas electorales y deliberativas propias de un espacio público en expansión (Moyano, 2008; Alonso, 2004; Sidicaro, 1993). Estas insinuaciones temáticas, de diseño y de forma discursiva se fueron estableciendo como un modo adecuado de llevar a cabo la tarea periodística. ¿Qué implicó este lento pero sostenido cambio? El abandono de las apelaciones facciosas para convertirse en medios de información y debate (sin que ello supusiera cesar en sus sesgos ideológicos) que les permitiera ampliar el círculo de lectores más allá del grupo de referencia, aproximándose así al modelo de prensa moderno². El gradual alejamiento del Estado como principal referente y destinatario de su contenido supuso una organización diferente de los contenidos, a partir de la

\footnotetext{
${ }^{2}$ Entiendo a la prensa moderna como aquella que se caracteriza por - entre otras particularidades construir a la noticia como una mercancía fundamental para su funcionamiento, junto con la relevancia -y continuidad - brindada a las diferentes secciones y suplementos, que permite diferenciar, de manera simple y drástica a la vez a muchos lectores distintos en un mismo diario. $Y$, además, encuentro en ella una actitud política, mas no facciosa, combativa o de mera propagación de mensajes electorales. Estas cualidades identifican, de manera general y a los efectos analíticos del presente artículo, la prensa moderna de su antecesora, la facciosa.
} 
utilización de columnas y subtítulos para ordenar la lectura, así como la inclusión de folletines y de numerosas publicidades (Pastormerlo, 2016; Ojeda, 2010; Rocchi, 1999). Aunque este modelo de la prensa gráfica recién tendrá su consolidación entre fines del siglo XIX y el comienzo del siglo XX (Moyano y Ojeda, 2015), resulta de manifiesto interés indagar de qué forma los nuevos discursos próximos a la prensa independiente, que debían caracterizarse por estructurar su fuerza en la opinión crítica de sus lectores independientes colisionaban con las viejas prácticas de difusión facciosas que continuaban considerando al diario como un mero folleto partidario. Sobre el cambiante devenir de la prensa, Sabato (2012: 212) aporta que:

Para incrementar las fuentes de ingreso, se modificaron los sistemas de distribución y venta, y si bien las suscripciones y los subsidios oficiales siguieron siendo fundamentales, muchos diarios instrumentaron la venta callejera. En Buenos Aires, La Tribuna fue pionero en ese proceso de modernización.

Para dar cuenta de esta compleja relación, analizaremos los editoriales ${ }^{3}$ de $L a$ Tribuna, El Nacional y La Nación Argentina durante los tres primeros meses de gobierno de D. F. Sarmiento. La elección de los diarios se sustenta en la trayectoria de los dos primeros, pues se trataba de los más longevos en circulación en la ciudad y en cuanto a La Nación Argentina, su estrecha relación con la gestión del saliente presidente B. Mitre, lo convirtieron, a pesar de sus pocos años de existencia, en un referente de la prensa porteña. Las inéditas condiciones que dieron lugar al triunfo de la candidatura de D.F. Sarmiento y las transformaciones que se estaban produciendo en la prensa periódica conforman un momento histórico de significación para el desarrollo del periodismo escrito en Argentina.

\section{Definiciones conceptuales}

Resulta necesario establecer cuáles los términos que conformarán el sustento teórico del análisis propuesto. Para comenzar resulta conveniente referirse a las categorías aportadas por Rivadeneira Prada, (1986: 227-229) quien propone seis formas de interpretar los editoriales: apologético, explicativo, expositivo, crítico, predictivo y admonitorio:

\footnotetext{
${ }^{3}$ La elección de los editoriales como corpus de análisis obedece a la significación que tiene esta columna en la superficie redaccional del diario. El editorial es, para la conformación de un diario, periódico, o revista, sin dudas, clave. Su relevancia es constitutiva del medio que representa. Cualquier información, comentario, descripción o conceptualización realizada en sus columnas atañe a la institución en su conjunto, sin mediar excusas. Sólo en esta sección no hay intermediarios ni terceros a quienes endilgar lo expresado. La responsabilidad es unívoca de modo absoluto: el medio gráfico se pronuncia allí, del modo más calificado e integral posible.
} 
Los estilos se dividen en expositivo: el editorialista enuncia hechos conectados desde un punto de vista particular, sin añadir conceptos que revelen una posición abiertamente definida; explicativo: manifiesta las causas de los acontecimientos, relaciona hechos en busca de una comprensión clara, a veces dialéctica, de las interrelaciones de los elementos del hecho; combativo: es característico de las posiciones doctrinarias en pugna con otras; se vale de la denuncia oportuna, de la explicación unilateral, de la exposición de motivos y hechos cuidadosamente seleccionados; crítico: hace las veces de juez en nombre de la 'opinión pública', cuida especialmente de labrar ante ese ente abstracto que dice representar, una imagen de 'imparcialidad' e 'independencia absoluta, es el editorial que prefieren los periódicos que se autoproclaman "órgano independiente"; apologético: pertenece a los órganos oficialistas y propagandiza las acciones del mismo; admonitorio: pretende el mantenimiento del equilibrio a través del cumplimiento de las normas, su tono es calmo y reflexivo, llama a la concordia, al orden, exhorta al cumplimiento de las reglas y las normas y, finalmente, predictivo: analiza situaciones y diagnostica resultados sociales y políticos, emplea el método de interpretación causal determinista.

Para reconocer las modalidades discursivas empleadas por los diarios, es oportuno recurrir a los aportes realizados por Ducrot (1997: 139):

Los auditores de un enunciado son todos aquellos que, por una razón o por otra, lo recepcionan, mientras que los alocutarios son las personas a las que el locutor declara dirigirse. Por su parte, el locutor es el que produce un enunciado, en tanto que el enunciador es a quien el locutor atribuye responsabilidad de una parte de lo que refiere.

En cuanto a la noción de periódico, se seguirá a Borrat (1989:419):

Si procuramos situar al periódico en el sistema político, entonces aparece-como los otros medios, los partidos políticos, los movimientos sociales y los grupos de interés- ocupando un nivel intermedio entre el conjunto de ciudadanos (que plantean sus demandas, sus apoyos, sus presiones) y las instituciones de gobierno que (apoyadas y presionadas) deciden (en favor de ciertas demandas y por tanto contra otras) y ejecutan sus decisiones. Pasamos a percibirle como intermediario, mediador, canal de mensajes que fluyen entre otros actores del sistema. Pero muchas veces tenemos que ampliar esta percepción: en lugar de mediar, el periódico actúa por su propia iniciativa, sea para premiar, sea para castigar a determinados actores. En todo caso, el periódico se perfila como un grupo de interés que actúa en función de los objetivos permanentes: influir y lucrar. 
Por último, se utilizará la categoría elaborada por Martini (2000:107): para ludir a la relación entre los medios gráficos y los lectores de la siguiente manera:

El pacto incluye desde el nombre, el formato y la tipografía, la presentación en la tapa, la diagramación y la ilustración; el nivel de lengua, el recurso a la deixis, las metáforas y comparaciones, los destacados, y los sistemas clasificatorios de las noticias en agendas temáticas diferentes. Se asume que el lector incluye en sus hábitos de consumo y en sus expectativas la lectura de las noticias construidas de una manera determinada. Se trata de una relación delicada, que puede romperse si se alteran las cláusulas del acuerdo, si el diario cambia parcial o totalmente sus modalidades de decir.

Los conceptos presentados permitirán realizar el examen de los editoriales a partir de aplicar la metodología cualitativa y la técnica de análisis de contenido.

\section{D.F. Sarmiento nuevo presidente}

El 12 de octubre de 1868, luego de una sencilla ceremonia ante la asamblea legislativa, D.F. Sarmiento y Adolfo Alsina asumieron la presidencia y vicepresidencia de la Nación. La situación general del país distaba de ser óptima. La guerra de la Triple Alianza estaba atravesando su cuarto año sin que los ejércitos aliados pudieran resolver la contienda de forma definitiva y en cuanto a las problemáticas internas, las dificultades económicas y la precariedad del Estado nación para imponerse sobre las provincias, amenazaban el proyecto centralizador que se había iniciado con B. Mitre. Apenas dos días después, El Nacional ${ }^{4}$ consideró oportuno dedicar su espacio institucional para ofrecer un análisis a modo de conclusión acerca de la obra de B. Mitre para señalar cuáles eran las condiciones en las que D.F. Sarmiento asumió la primera magistratura:

Al cerrarse una época y abrirse otra nueva es conveniente que la prensa tome balance de la situación en que quede el país, en que lo toma el gobierno del señor Sarmiento; porque, sobre este antecedente, será establecida su responsabilidad. (...) Heredamos la guerra del Paraguay, aunque a punto de terminar. Esa guerra nos habrá costado la sangre de diez mil hermanos nuestros, carne de nuestra carne y unos 25 ó 30 millones de pesos fuertes. Con la mitad se hubiera hecho esta guerra; pero faltó la administración en el ejército y en la casa de gobierno, y ha negociado el que ha querido (...) Pero la guerra ha sido justa en

\footnotetext{
${ }^{4}$ El Nacional fue fundado por el Dr. Dalmacio Vélez Sarsfield, el $1^{\circ}$ de mayo de 1852 . Su editor responsable fue Cayetano Casanova. Dejó de editarse el 28 de agosto de 1893. En sus columnas escribieron Domingo Faustino Sarmiento, Bartolomé Mitre, Vicente Fidel López, Nicolás Avellaneda, Juan Bautista Alberdi, entre otros.
} 
el punto de partida y de ella no tiene responsabilidad alguna el general Mitre. La guerra nos buscó porque del Paraguay disponía un tirano bárbaro con sueños de ambición (...) Pero todo cede el paso a dos hechos que las administración pasada deja a la presente: $1^{\circ}$ una deuda que no bajará de 60 millones de pesos fuertes; $2^{\circ}$ la desmoralización en los empleados y con los que el gobierno tuvo contacto o negocio consentidos. (...) Costumbre hecha en el gobierno de regalar sueldos sin cargo, de hacer otros donativos a los empleados amigos, obsequios que el Congreso no ha autorizado. (...) Cumple a la administración presente tomar los hechos existentes en cifras en estados exactos y publicarlos: que se sepa lo que ellos reciben. Hacer actos de justicia con los que detentan dinero del Estado es de una alta e imprescindible necesidad sometiendo el juicio a la justicia Nacional. Con buena voluntad, constancia y trabajo, mucho se puede hacer ${ }^{5}$.

El editorial combativo (Rivadeneira Prada: 1986) eligió como enunciador al ex Presidente para poner de manifiesto la herencia financiera que le dejaba al nuevo mandatario y al ánimo general de los trabajadores en relación a sus obligaciones, debido a la discrecionalidad denunciada por el locutor. De esta forma, en su rol de actor político (Borrat: 1989) se dirigía a sus alocutarios ofreciendo una particular forma de posicionarse respecto a $B$. Mitre: reconocía la necesidad de la guerra que aún no concluía, pero señalaba los errores al realizarla. En cuanto a la administración general de los asuntos de Estado, la falla tenía su origen en una pésima administración de los fondos públicos que parecía beneficiar sólo a algunos allegados a B. Mitre. El pacto de lectura también incluía el apoyo al nuevo mandatario. Al respecto, es preciso destacar una ambigüedad en su enunciado, ya que podemos detectar atisbos de un intento por parte del locutor de reconocer la relevancia de los auditores para juzgar una gestión, reconstruyendo así la función de la prensa como vigía del interés público; sin embargo, también se puede hallar un manifiesto apoyo a Sarmiento que diluye aquel posicionamiento. Esa contradicción revela una tensión clave para interpretar el desenvolvimiento de la prensa: ni acabadamente moderna ni tampoco facciosa. Se invocó a los auditores, pero a la vez no parecía sencillo abandonar el grupo de pertenencia y sus claves de interpelación.

La Tribuna $^{6}$, dos días después, también se interesó por establecer su posicionamiento acerca del nuevo gobierno. En el editorial titulado "Un gobierno de paz y de trabajo", buscó diferenciarlos de la siguiente forma:

\footnotetext{
5 “Balance de una época”, El Nacional, 14-10-1868, año XVII º6735, página 2.

${ }^{6}$ La Tribuna se editó desde el 7 de agosto de 1853 hasta el 27 de septiembre de 1880 . Sus redactores principales fueron Juan Ramón Muñoz, Héctor y Mariano Varela. Resulta significativo citar a Galván Moreno (1944: 198) quien aporta lo siguiente: «Fue un periódico de muy larga vida. En 1872 en competencia con El Nacional, lanza ediciones por la tarde».
} 
Gobierno esencialmente político, el General Mitre hacía sentir sus acción política y su influencia política en las provincias argentinas, pero rara vez su acción como gobierno de trabajo, como gobierno de progreso material, como gobierno de iniciativa en todas aquellas conquistas pacíficas que llaman al ciudadano a una vida en que, adquiriendo conciencia de su personalidad y de lo que ella vale, mira con horror la guerra y sobre todo, esas montoneras salvajes en que ellos van a pagar con sangre generosa los caprichos y ambiciones de los eternos explotadores de la patria. Ese ha sido uno de los errore del gobierno del general Mitre, como es uno de las grandes esperanzas del gobierno del señor Sarmiento, el programa de trabajo y de labor material, bajo cuyos auspicios sube. Cada hombre tiene una manía (...) Washington tuvo la manía de la independencia de su patria(...) Sarmiento tiene una manía también: la manía del trabajo, la manía de la educación del pueblo(...) El general Mitre hizo un gobierno esencialmente político. El señor Sarmiento, una vez en posesión de hacer prácticas las ideas que populariza hace treinta años, hará un gobierno de trabajo, un gobierno de paz, que no podrá menos que contar con el apoyo de todos los que se interesen que ese trabajo dé sus frutos de riqueza y esa paz se consolide por doquier? ${ }^{7}$.

El locutor escogió un enunciado combativo para configurar su pacto de lectura con sus alocutarios, acerca de D.F. Sarmiento. La dicotomía planteada le permitió referirse al enunciador negativo ${ }^{8}$ poniendo de manifiesto sus escasas condiciones de gobernante y su notorio afán político faccioso. Por el contrario, la esperanza ante el nuevo gobierno con el cual coinciden en sus principales objetivos, los impulsó a formular un enunciador positivo, pero no sólo para sus alocutarios, pues al admitir sus "manías" buscaban aproximarse a todos los auditores, a partir la inversión de sentido de los términos empleados: un defecto convertido en virtud. Así el locutor buscaba posicionarse como un actor político que se permitía expresar su ideario fortaleciendo su inclinación con argumentos que pretendían ser racionales o que al menos no pretendían suscitar una confrontación violenta. Por último, es preciso destacar que en el cierre del enunciado el locutor trató de implicar a todos los auditores en la magna tarea que debía realizar el gobierno para mejorar la situación. Esta interpelación podría considerarse como un intento, insuficiente, de constituirse como un actor político moderno que prioriza el bien común por encima de los intereses partidarios. Las coincidencias que se podrían hallar entre los editoriales de El Nacional y La Tribuna resultan aún más significativas si nos aproximamosa a indagar en las consideraciones

\footnotetext{
${ }^{7}$ La Tribuna, 15-10-1868, año XVI N4468, página 2.

${ }^{8}$ Denomino enunciador negativo cuando el locutor lo establece como responsable de equivocaciones, defectos o graves falencias, sea de forma individual o grupal. En cambio, el enunciador positivo comporta una operación semántica opuesta. Se utilizará esta distinción cuando los enunciados posean más de un enunciador.
} 
vertidas en el espacio institucional de La Nación Argentina ${ }^{9}$. El 15 de octubre de 1868, en "El estreno del sr. Sarmiento", se apresuró a denunciar malos tratos con los subordinados:

Un presidente corriendo a patadas a sus empleados en el salón de gobierno ${ }^{10}$. Nosotros, como muchas personas, como la mayoría del país, conociendo el carácter violento y extravagante del sr. Sarmiento, al verle subir al gobierno (...) nos preparábamos a presenciar las medidas y los actos más inesperados. Pero nadie creyó ni pudo pensar que el sr. Sarmiento, al segundo día de su gobierno, se dejara arrastrar por su genio al extremo inaudito de que vamos a dar cuenta a nuestros lectores (...) El joven empleado pasó al despacho del S.E. el señor Sarmiento y le manifestó que el subsecretario le había indicado que lo viese para manifestarle su deseo de tener su destitución por escrito. Sarmiento dejó unos papeles que tenía en la mano y fijando los ojos en el empleado, le preguntó con voz alterada:

-¿Cómo se llama usted?

-Carlos Cuapeaurouge, contestó el joven

-Ah -dijo Sarmiento saltándosele los ojos- ¿Usted es el que escribe en la Nación Argentina?

-Señor, ya no escribo en La Nación Argentina, así lo he declarado al Dr. Vélez bajo mi palabra. Puede preguntarle al Dr. Gutiérrez.

-Aaah - vociferó el Sr. sarmiento - ¿con que usted desmiente al Dr. Vélez?

-Yo no desmiento a nadie, señor Presidente. Desde que sufrí el primer interrogante, he declarado que no había escrito una palabra en la Nación Argentina. Y cuando se me preguntó si simpatizaba con las ideas de ese diario, no teniendo costumbre de mentir ni de traicionar mis sentimientos, he contestado francamente que sí (...)

El Presidente de la República no pudo contenerse al oír aquellas palabras. Levantándose de la silla con los signos del furor más extraordinario, gritó: -iSalga usted de aquí só pillo insolente! Y se precipitó sobre él con el puño levantado para golpearle (...) Sarmiento fuera de sí, SE PUSO A CORRERLO COMO

\footnotetext{
${ }^{9}$ La Nación Argentina fue fundada el 13 de septiembre de 1862 por J.M. Gutiérrez. Circuló hasta diciembre de 1869. El 4 de enero de 1870 B. Mitre lo convirtió en La Nación. Aún sigue editándose y es uno de los diarios más longevos del país.
}

${ }^{10}$ Las negritas pertenecen al original. 
UN DESAFORADO POR TODO EL SALÓN DE GOBIERNO TIRÁNDOLE PUNTAPIÉS ${ }^{11}\left(\right.$...) Este hecho no necesita de ningún comentario ${ }^{12}$.

El editorial combativo combinó dos formas discursivas complementarias para construir en sus alocutarios la inestabilidad emocional y el rudo manejo de las relaciones con sus allegados que tenía el enunciador. La reconstrucción ficcional del diálogo y la hipérbole conforman una estrategia expositiva que pretende circunscribir un sólo sentido a su enunciado institucional: el mal carácter del enunciador es un problema de Estado. El locutor, de esta forma, propuso establecer como parte importante de su pacto de lectura una diferencia acerca de sus congéneres: antes que analizar el pasado, era necesario exponer a los auditores el temperamento del enunciador. Sin embargo, el locutor, en su rol de actor político, eligió un episodio en el cual estaba implicado, pues el motivo de la discusión era la participación del empleado como antiguo redactor y asiduo lector del locutor. Así, en un episodio que no reviste tamaña relevancia para una gestión (ya que discusiones y despedidos suelen ser frecuentes en cada cambio de mandato) la acentuación dada a la arbitrariedad de la decisión del enunciador (que pone de manifiesto su intolerancia hacia la crítica, a pesar de que sólo se trata de una versión ficcionalizada) permite elucubrar que aunque el empleado haya perdido su trabajo, el locutor obtuvo una convalidación del posicionamiento opositor elegido: debía ser opositor, pues el enunciador allí lo había colocado.

A pesar de los pocos días que llevaba la administración de D.F. Sarmiento, la discusión estaba planteada en términos dicotómicos. Si El Nacional y La Tribuna, explicitaban su apoyo ofreciendo argumentos que evidenciaban un análisis de la situación y que no cejaba en su descripción negativa acerca de las condiciones en que debió asumir, debido a las falencias de B. Mitre. Por el contrario, La Nación Argentina, inauguró su rol de medio opositor resaltando las peores cualidades de D.F. Sarmiento, sosteniendo su posicionamiento en una particular sinécdoque: una pelea con un empleado ilustra (y anuncia) su desempeño y en consecuencia, los resultados que debían esperarse de su gestión. Resulta significativo advertir que ninguno de los diarios que acompañaban a D.F. Sarmiento se interesaron en responder sobre el editorial de La Nación Argentina, soslayando la difamación, acaso para restarle veracidad e importancia. El Nacional, en el editorial El tesoro nacional ${ }^{13}$, continuó con su examen de la coyuntura, ajustando su discurso a las dificultades económicas que debía afrontar D.F. Sarmiento:

El gobierno del Sr. Sarmiento ha encontrado las arcas vacías y graves compromisos que le ha dejado sobre él la anterior administración: esta es la verdad. Pero esto no quiere decir de ninguna manera que el nuevo gobierno no

\footnotetext{
${ }^{11}$ Las mayúsculas pertenecen al original.

${ }^{12}$ La Nación Argentina, 15/10/1868, Año VII, N²32, página 1.

${ }^{13}$ El Nacional, 16/10/1868, Año XVII, N 6728, página 1.
} 
cuenta con los recursos necesarios para su vida propia y para seguir atendiendo con regularidad a todos sus compromisos, por más onerosos que sean. Al otro día de su entrada, las arcas del Tesoro Nacional que encontró sin un solo peso, tenía ya quinientos mil patacones en caja. El crédito de la nueva administración se ha hecho sentir inmediatamente. Los bancos le han ofrecido sus fondos, muchos capitalistas particulares, amigos leales del nuevo gobierno le tienen abiertas sus cajas (...) Esta es la obra puramente del crédito de que goza una administración que ofrece toda clase de de garantías al país y que cuenta con el apoyo moral y material de la gran mayoría del pueblo. Un gobierno que tiene estos elementos de poder no puede menos que ser un gobierno sólido.

El enunciado combativo transformó la grave situación económica-financiera del Estado nacional para consolidar entre sus alocutarios la importancia de la figura del nuevo presidente como garante de la rápida resolución del acuciante problema de los fondos para atender los compromisos contraídos. El enunciador, según el locutor, era el único responsable. Sin embargo, no se detuvo en la frecuente diatriba contra la gestión saliente, sino que escogió establecer una comparación entre la confianza política que gozaba el nuevo Presidente, con el apoyo económico que le ofrecían los bancos y particulares. La metonimia no sólo beneficiaba a D.F. Sarmiento, sino que también permitía reflexionar acerca de la situación de B. Mitre al final de su mandato. Pues si no tenía crédito, ¿tenía respaldo? o, acaso, lo tuvo y lo dilapidó como a los dineros públicos. Sin dudas B. Mitre continuó teniendo apoyo del espacio público (Dìaz: 2012) porteño, pero el locutor, en su ejercicio como actor político, pretendía propiciar una corriente de opinión adversa al saliente mandatario.

La Tribuna, apenas un día después que El Nacional, también se refirió a la estrechez monetaria de la nueva administración:

Todo Gobierno representa para nosotros dos fases culminantes a los ojos del pueblo cuyos destinos rige: una que se le dá el origen de su elección. Otra que se le dá la composición individual de ese Gobierno (...) Es ni más ni menos, lo que sucede con el Gobierno del sr. Sarmiento. Su candidatura fue levantada ocho meses antes de la elección. Su candidatura ha resistido a uno de los exámenes más tenaces, más minuciosos, más apasionados porque quizá haya pasado candidatura alguna en toda esta parte de la América Española (...) Un Gobierno que nace con los antecedentes de éste y así constituido, debía inspirar, e inspira ilimitada confianza del pueblo. Como ayer lo anunciamos, varios de nuestros principales capitalistas han ofrecido recursos al Gobierno por si los necesitaba, dando así una doble prueba del patriotismo que los ha guiado, y de la confianza que tienen en un Gobierno que se inaugura levantando la bandera de la moralidad algo despedazada durante la administración anterior, no porque creamos que faltase moralidad al Presidente $y$ sus Ministros, sino porque 
consentían en torno suyo, ciertos escándalos y abusos que habían introducido cierto desquicio, que solo una mano firme y una voluntad de fierro podrá contener. $Y$ créalo el pueblo: todos esos abusos, esos favoritismos indignos, a cuya sombra se han labrado grandes fortunas, haciendo personajes opulentos de los que ayer eran pobretones insignificantes, van a cesar inmediatamente. La voluntad del nuevo Gobierno a este respecto es decidida, inquebrantable ${ }^{14}$.

El enunciado combativo conformó su estrategia discursiva presentado a sus alocutarios de qué forma había ascendido su enunciador a la Presidencia, para evidenciar que su apoyo tenía bases sólidas, comprobables y que podían constituirse en argumentos políticos válidos frente a cualquier debate, de esta forma reforzaba, además, su pacto de lectura. El locutor, en la segunda parte del enunciado, aludió al sólido apoyo obtenido por el enunciador para gobernar, traducido en créditos y respaldos financieros. Es posible colegir que sus metonímicas aseveraciones estaban más dirigidas a los auditores del espacio público porteño que a sus alocutarios: el sostén de la sociedad (y de algunos medios) significaba un sostén pecuniario que no debía ponerse en duda.

La Nación Argentina no tenía las mismas preocupaciones, su interés estaba orientado en defender la gestión de B. Mitre. Su <<agenda editorial»> estaba vuelta hacia el pasado para influir en el presente sobre la probidad del ex presidente. En el editorial "Las acusaciones del Presidente contra el Gobierno del General Mitre", sostuvo lo siguiente:

El Presidente ha lanzado acusaciones terribles contra el gobierno del general Mitre. Se ve por ellas mismas que son calumnias ridículas, pero desde que algunas se fundan en hechos que pueden haber sido asegurados al Sr. Presidente vamos a ocuparnos de ellos. El Sr. Sarmiento desde el alto puesto de Presidente, acusa al General Taboada "de ladrón público, que recibía del Tesoro Nacional sumas para pagar las fuerzas a sus órdenes y se quedaba con ellas; y el Gobierno del general Mitre, de haber comprado a los Sres. Taboada por este medio para que lo sirvieran en la lucha electoral, pagándole mes a mes estas sumas cuando no se pagaban los sueldos y deudas más sagradas" (...) Un pacto entre el General Mitre y el General Taboada para dejar a este robar los tesoros del Estado en cambio de trabajos electorales a favor de una candidatura indicada por él, es una convicción de los hombres que rodean al Sr. Sarmiento y al formular la terrible acusación que contra ellos ha formulado el Presidente, ha asumido una seria responsabilidad. Crímenes de esta naturaleza ni pueden quedar sin castigo. Un Presidente no puede quedar en su puesto, desde que se haya convertido en un

14 “El prestigio del gobierno nacional”, La Tribuna, 17/10/1868, Año XVI N4410, página 1. 
gran calumniador. A estas extremidades lo llevan los hombres funestos de que se ha rodeado ${ }^{15}$.

El enunciado combativo se ocupó de desagraviar a su enunciador frente a las graves acusaciones de corrupción, para no permitir que su figura cayera frente al oprobio del espacio público porteño, respetando así su pacto de lectura. Pero además de ejercer una defensa irrestricta de su enunciador, soslayando que parte de la información aludida es cierta, pues no trepido en manifestar que su enunciador negativo debía abandonar el cargo. Aunque el locutor sabía que su pedido era extremo e impracticable, al igual que sus alocutarios, acaso la diatriba permitiría igualar el impacto producido por la denuncia.

\subsection{Los estilos del debate}

Los debates entre los diarios podían conformarse -al menos- de dos maneras: abordando el mismo tópico, confrontando de manera directa, frontal e inmediata, como si se tratara de una discusión sincrónica. La prensa facciosa es el paradigma de este comportamiento.

Con el advenimiento de un nuevo modelo periodístico que se inició a mediados del siglo XIX y se consolidó en las primeras décadas del siglo XX, los diálogos se volvieron menos violentos y también (acaso como una consecuencia del cambio de reglas del mercado de prensa y de los consumos culturales) más alusivos, entablando un solapado diálogo de referencias comunes en los cuales el pacto de lectura y el decoro en las expresiones eran los límites a respetar, sin que ello signifique que no se quebraran en más de una ocasión ${ }^{16}$. Esta forma, que podríamos denominar premoderna de debate, puede hallarse en el siguiente editorial de El Nacional, "Actos de Gobierno":

Si no hubiera venido concebida de antemano una oposición sistemada de un partidito de cuatro gatos, despechados por la derrota, excusaríamos gustosos el comentario de los actos del gobierno, dejándolos librado al buen juicio público. Pero la calumnia algo deja, y es preciso hacer limpieza de la cizaña que siembra el odio. La independencia con que ha procedido el presidente Sarmiento, en la elección de las personas con que formó el ministerio, y llenó otros puestos públicos de importancia también, independencia de vínculos personales, y de vínculos políticos, es lo que más realza a nuestro juicio, el buen criterio del sr.

\footnotetext{
${ }^{15}$ La Nación Argentina, 1/10/1868, Año VII, N² 247, página 1.

${ }^{16}$ La transformación de la práctica periodística, que incluye las pautas de lectura por parte del público, deben considerarse como un proceso ambiguo que sólo encontró su forma acabada en las primeras décadas del siglo $\mathrm{XX}$.
} 
Sarmiento (...) El sr. Sarmiento no pregunta, ni quiere saber las opiniones adversas o favorables de nadie al respecto de su candidatura y un sentimiento natural de su generosa espíritu lo inclina un tanto hacia los vencidos. Para los puestos públicos, busca hombres honrados en primera línea y la idoneidad en segunda, eso muestran sus primeros decretos. (...) Es siempre conveniente a un Gobierno y a un partido leer lo que la oposición dice, que algo hay a aprender en sus censuras y se lee con gusto cuando esas censuras se mantienen en el buen terreno, en la cultura del lenguaje, en la seriedad de la discusión, etc. (...) No hay objeto bueno en leer lo que dice una oposición que se presenta de arlequín en la plaza pública, haciendo o diciendo truhanerías $>>{ }^{17}$.

El enunciado crítico y a la vez combativo permite colegir la tensión entre la vieja forma de hacer prensa (recurriendo a frases hirientes) con un incipiente modo de expresarse en favor de un debate correcto y formal propio de un actor político moderno que busca influir en el espacio público. El locutor aprovechó una pretérita acusación de su enunciador, (al cual sólo aludió, pero de forma violenta), para reforzar su pacto de lectura con sus alocutarios, las agresiones pertenecían a la oposición y quienes acompañaban al Presidente estaban dispuestos a recibir críticas sobre su desempeño, aunque la forma de referirse a su enunciador no parecía demostrarlo. El intenso diálogo sostenido por La Nación Argentina y El Nacional no significó para La Tribuna un asunto de interés, por el contrario prefirió acentuar su acompañamiento a la gestión de D.F. Sarmiento aportando argumentos que le permitieran constituirse como un actor político moderno, interesado en brindar al espacio público porteño una exposición prolija y sin exabruptos de la actualidad. El editorial publicado el 3 de noviembre de 1868 , bajo el título "Vamos bien", es un ejemplo de su posicionamiento y de su modo discursivo:

Fortifícanse nuestras esperanzas de que la Administración actual de la República ha de producir bien, mucho bien para el país. Viene esto de la decidida tendencia en que la vemos empeñada por reformar lo que necesita reforma, por hacer economías que la buena Administración aconseja y sobre todo por dotar al país de instituciones y mejoras que tiene forzosamente que producir bienestar y paz en el porvenir. El Ministro del Interior (...) organiza el Departamento Topográfico para responder a lo mucho por hacer en la República, haciendo al mismo tiempos economías en otros ramos de la Administración, compatibles con el buen servicio (...) El Ministro de Hacienda por su parte penetra en la Administración que le compete (...) visita la aduana y procura no solamente mejorar esa administración fuente de la renta, al mismo tiempo que trata de regularizar la deuda nacional, sino también que forma un plan completo de reforma cuya realización tiene forzosamente que dar brillantes resultados. (...)

\footnotetext{
${ }^{17}$ El Nacional 23/10/1868, Año XVII, N6734, página 2.
} 
En una palabra el Gobierno en masa levanta en alto la moral administrativa y de los pocos días transcurridos deja ver que una vez montada la administración el país va a entrar por primera vez en la anhelada huella de las mejoras que traerán la reorganización nacional ${ }^{18}$.

El enunciado apologético se interesó por reforzar ante sus alocutarios su pacto de lectura: el enunciador estaba realizando una gestión auspiciosa y era muy probable que cumpliera con sus principales objetivos: sanear la economía y fortalecer el Estado nacional. Ante ello la oposición que pudiera existir en los auditores y en el espacio público no era relevante, pues las obras y medidas de gobierno demostrarían que se había elegido el modo correcto para resolver los problemas. El aval del locutor junto a la prolija exposición de los argumentos, soslayando agresiones o denuncias, favorece la comprensión del modelo de periodismo que trataba de construir, diferenciándose así de sus congéneres.

La Nación Argentina continuaba, por su parte, más preocupada por salvaguardar el buen nombre y honor de B. Mitre que por discutir las medidas de la actual gestión. O quizás, podría afirmarse que las discutía para establecer diferencias entre ambas. Al cuimplirse un mes de la administración de D.F. Sarmiento, el diario dedicó sus columnas editoriales para ofrecer un balance crítico:

Los órganos oficiales muy complacidos pasan revista a los actos del gobierno Nacional pero su fantasía les hace ver lo que no existe, desfigurándolo todo. Dos categorías de hechos nos presentan. Abusos que han corregido dejados por la anterior administración. Medidas importantes sobre asuntos resueltos. Sobre los abusos, nos recuerdan los cupones falsos, los cometidos en la capitanía del Puerto y una que otra bagatela. Toda administración tiene que corregir abusos, es una lucha incesante, y los que mencionan son imputables a subalternos no al gobierno. Las medidas que ha tomado el señor Sarmiento son funestas, porque la política que las inspiró lo es. (...) Las destituciones y persecuciones ¿no han levantado una oposición que el mismo Sarmiento no es capaz de apreciar? ¿Qué resolución ha tomado que no sea un abuso y un escándalo? Un mes de gobierno ha bastado para que el país comprenda que es imposible semejante autoridad.(...) Deténgase el Presidente, lleva al país a un abismo y tal vez no podrá hacer a tiempo su maleta ${ }^{19}$.

El enunciado combativo no sólo atribuyó a su enunciador negativo la responsabilidad de todas las dificultades que atravesaba el país, con sus alocutarios de acuerdo a su pacto de lectura, sino que además se permitió reconocer algunos errores de la administración anterior, pero sin que ello supusiera una modificación de su pacto de

\footnotetext{
${ }^{18}$ La Tribuna, 3/11/1868, Año XVI N4426 Página 2.

19 “Un mes de gobierno”, La Nación Argentina, 25/11/1868, Año VII, N² 266, página 1.
} 
lectura con sus alocutarios: los escasos incidentes no eran adjudicables a su enunciador positivo. En cambio, cada dificultad señalada por el locutor era responsabilidad exclusiva de su enunciador negativo. La dicotomía planteada, si bien no representaba una novedad para sus alocutarios, acaso para los auditores del espacio público porteño supusiera una argumentación inconsistente. Sin embargo, llevando al extremo su manifiesta oposición, se permitió formular una advertencia a su enunciador negativo.

Las condiciones establecidas por La Nación Argentina para afrontar la controversia entre el actual gobierno y el anterior no fueron rechazadas por El Nacional.

Proclamada la presidencia del Sr. Sarmiento, nadie se acordó de los vencidos en la lucha electoral, quienes no se cuidaron de lanzarles acusaciones ilegítimas, sólo por el deseo de lastimar a su contrario. A pesar de esto, se evitó molestar con la verdad a los hombres que dejaban de gobernar la República, callando muchos actos indecorosos, silenciando la ruina en que se entregaba una herencia que solo por patriotismo pudo aceptarse. Aún se hizo más, porque el nuevo Gobierno ofreció al Sr. Mitre nombrarlo jefe del ejército de operaciones en el Paraguay (...) Pero sucedió que los vencidos tomaron la generosidad por debilidad, y antes de recibirse del mando el Sr. Sarmiento, bajaron a la arena de injurias escandalosas, denigrantes de las personas y hasta de sus intenciones, que es hasta dónde puede llegar el furor de una oposición sistemada (...) Las ruinas asustarían al más valeroso y decidido; pero el Gobierno actual, en vez de arredrarse, ha conjurado esos males, ha levantado las dificultades, y sigue con paso firme no en busca de guerras, ni de revueltas, sino de la paz y del progreso $^{20}$.

El locutor empleó un enunciado combativo para encumbrar a su enunciador positivo resaltando las dificultades heredadas gracias a las equivocaciones de su enunciador negativo, no sólo para insistir frente a sus alocutarios acerca del apoyo que merecía el actual gobierno, sino también para reprimir cualquier posibilidad de que cundiera una interpretación antagónica entre los auditores del espacio público. Además, es preciso consignar, expuso sus argumentos sin caer en términos groseros sin por eso disminuir en su accionar como actor político. Por el contrario, sus convicciones acaso hayan adquirido más firmeza - más allá del ámbito de sus alocutarios - gracias a su moderación en el lenguaje. Esta cualidad, que lentamente se irá consolidando durante el último tercio del siglo XIX y principios del siglo XX, es posible encontrarla con mayor frecuencia, en el lapso analizado, en La Tribuna. Quizás esto se deba a que se abocó a la tarea de respaldar a D.F. Sarmiento sin detenerse tanto en las discusiones con La Nación Argentina. En el editorial publicado el 18 de diciembre de 1868, para celebrar

20 “Las confesiones del gobierno anterior”, El Nacional, 21/12/1868, Año XVII N6783, página 2. 
el inicio de las obras para desarrollar la red del telégrafo en el país, puede advertirse el comportamiento del diario:

(...) Antes de ahora, hemos dicho que Sarmiento y su ministerio no harán un gobierno de política y de intriga, sino un gobierno de paz y de progreso, de iniciativa constante y de trabajo continuo, que en pocos años ha de dar a la República lo que en los muchos corridos no han sabido o no han querido darle, los que sólo se han ocupado de hacer política y elecciones (...) Hoy tenemos la satisfacción de anunciar que el gobierno general ha dispuesto destinar un millón de pesos fuertes, que tiene ya, para la construcción de telégrafos eléctricos que recorrerán la República de San Juan y Jujuy hasta Buenos Aires ligando entre sí todas las provincias. Difícilmente podríamos llevar a la República noticia más importante, ni acto más práctico de gobierno (...) El porvenir es de esas obras y de sus autores y para los pueblos no hay lenguaje más claro que el de los hechos ${ }^{21}$.

El enunciado apologético tuvo como principal objetivo destacar los logros de D.F. Sarmiento ante los auditores para que sus alocutarios pudieran sentirse confiados acerca del acompañamiento brindado al locutor y al enunciador. La tarea que estaba cumpliendo su enunciador era digna de elogio, tal como lo proponía el locutor en su pacto de lectura. Las alusiones a la oposición y al pueblo le brindan al enunciado una moderación que lo distinguen como un actor político más próximo a la corrección en sus exposiciones que a la diatriba y a la polémica.

A la favorable disposición de La Tribuna y al beligerante apoyo dedicado por EI Nacional a D.F. Sarmiento, La Nación Argentina implementó una estrategia que buscó forzar el análisis en perspectiva histórica para evaluar la gestión del Presidente en funciones sólo en relación a B. Mitre y su gobierno. Es por ello que el interlocutor predilecto no era La Tribuna, pues sus alusiones a la oposición no bastaban para conformar un debate en las condiciones que podrían ser favorables para su línea editorial. Una obra o impulso de D.F. Sarmiento a un sector o hacia el desarrollo de una tecnología no revestían el interés suficiente para transformarlo en polémica, pues cabía la posibilidad de tener que admitir que debió hacerse antes. Sin embargo, El Nacional sí era un rival deseado, porque también realizaba una operación discursiva semejante a La Nación Argentina, aunque con intereses opuestos, es decir aludían al presente para centrarse en el pasado, pues allí estaba cifrado su interés. Es por ello que una de las últimas editoriales políticas de 1868, La Nación Argentina la dedicó a confrontar la actual gestión con la antecesora.

Por móviles los más indignos y pequeños el Sr. Sarmiento, olvidando sus propias responsabilidades, se ha propuesto atacar y desacreditar la administración del

21 “Magnífica resolución del gobierno Nacional”, La Tribuna, 18/12/1868, Año XVI N4461, página 1. 
General Mitre sin omitir medios por más reprobados que sean. Ha dado órdenes y suministra datos a sus órganos por las oficinas públicas, para probar que la administración del General Mitre ha sido la más perniciosa, culpable y criminal que ha tenido el país. La política exterior, la política grande, los indios, las montoneras, la guerra, las erogaciones del tesoro, las elecciones, las intervenciones, todo en fin, se ha presentado por Sarmiento, como el resultado del error, del fraude, del crimen y de los más malos propósitos (...) Queda sin embargo probado que los pocos atentados cometidos contra la vida de ciudadanos, durante la administración del General Mitre, fueron obra del Sr. Sarmiento, Gobernador de San Juan, que ordenó y aprobó los degüellos y bárbaras matanzas con cuya sangre se enlodó. El Gobierno del General Mitre desaprobó la conducta del señor Sarmiento y esa desaprobación, como otras, han sido la causa del odio y rencor que ha nutrido en su corazón el señor sarmiento y que ha venido a revelar cuando se ha encontrado en la posición que se encuentra, arrojado la careta con que se cubría $(,,$,$) El señor Sarmiento y los$ pocos amigos suyos, creyeron que el General Mitre debía apoyar su candidatura. No les bastaba que se mantuviese ajeno a la lucha, y los mismos que buscaban su concurso, ante esta actitud digna, se desataron contra él y veían hasta el asesino del hijo del señor Sarmiento en quien poco antes buscaron un apoyo para usurpar la soberanía popular. Esta es la causa de los ataques a una administración que nadie menos que el señor Sarmiento podía atacarla. La pureza de la administración del general Mitre, se ha de develar más y más con los ataques apasionados que el señor Sarmiento le hace ${ }^{22}$.

El enunciado combativo erigió su argumentación para resguardar a su enunciador positivo indicando las motivaciones que tenía su enunciador negativo para comportarse con tanta iniquidad una vez asumida la Presidencia. No resulta un detalle que el locutor haya presentado a sus alocutarios una versión de la situación conflictiva entre D.F. Sarmiento y B. Mitre que remite de manera directa al pasado, no sólo le resultaba conveniente por la estrategia discursiva consagrada en su pacto de lectura, sino también porque sostenía a su enunciador positivo como el miembro más conspicuo y determinante del espacio público. En consecuencia, su enunciador negativo era apenas un despechado y por lo tanto sus denuncias eran sólo un recurso para satisfacer su deseo de venganza.

\footnotetext{
22 “La administración del General Mitre y el Sr. Sarmiento”, La Nación Argentina, 8/12/1868, Año VII $\mathrm{N}^{\circ} 277$, página 1.
} 


\section{Conclusiones a modo de cierre}

La asunción de D.F. Sarmiento a la presidencia suscitó en La Tribuna, El Nacional y La Nación Argentina posicionamientos editoriales diferentes, que conformó formas de intervención periodísticas disímiles. La Tribuna y El Nacional decidieron acompañar la gestión desde su inicio, aunque con estrategias discursivas diferentes. La Tribuna optó por respaldar al Presidente resaltando sus medidas, buscando conferirle legitimidad dentro del espacio público a partir de sus editoriales apologéticos, en los cuales no se permitía más que alusiones y referencias que si bien eran firmes, no recurrían a los adjetivos groseros ni a las diatribas violentas. Sus columnas institucionales, aunque carecían de un equilibrio (o al menos de una intención de lograrlo) entre las diferentes opiniones políticas, pues su apoyo a Sarmiento era evidente, sin embargo, su desempeño, durante los últimos meses de 1868, podría considerarse como un ejemplo de la lenta pero sostenida transición de la prensa de facción a la prensa moderna. Pues había abandonado las invectivas, pero no tenía aún la independencia necesaria (aún en meros términos formales) ni parecía preocuparle.

El Nacional, en cambio, adoptó un lenguaje más agresivo para sostener su apoyo a D.F. Sarmiento. Sus editoriales se mantuvieron en un estilo combativo, forzando la interpelación directa de sus alocutarios y principalmente de los auditores. Sus adjetivaciones y modismos, propias de una discusión acalorada, conformaron una dicotomía inalterable: un enunciador positivo (D.F. Sarmiento) y uno negativo (B. Mitre). Su rol de actor político estuvo signado por la polémica partidaria, de tal forma que las medidas de gobierno eran apenas un motivo para continuar con sus ataques a los opositores. Sus apelaciones al bien común, al pueblo y a la opinión pública conformaron las únicas ocasiones (breves, por cierto) en que cejó en su beligerancia y trató de impostar una madurez periodística que nunca pudo (ni quiso) conquistar. La Nación Argentina, acaso sin proponérselo, fue el receptor que El Nacional precisaba para darle consistencia (y sentido) a sus enunciados. El debate sostenido entre ambos tuvo su interés dirigido en establecer la calidad del gobierno de B. Mitre y en sus diferencias con D.F. Sarmiento. Es por ello que sus editoriales también fueron combativos, confinando a los problemas del presente a un rango subalterno, pues no eran importantes sino en función de cómo habían sido abordados por el ex mandatario. $\mathrm{Y}$, como era de esperarse, su enunciador negativo predilecto fue Sarmiento, pero no tanto por sus falencias en su gestión, sino por sus malas decisiones en su etapa como gobernador de San Juan. Incluso el locutor llegó a afirmar que las únicas muertes durante el mandato de su enunciador positivo eran absoluta responsabilidad de su enunciador negativo. La Nación Argentina tuvo, durante el período analizado, su interés cifrado en las alternativas de la presidencia que precedió a D.F. Sarmiento. Y pudo encontrar en El Nacional un contrincante que aceptó las condiciones del debate, tanto en su contenido como en sus formas. Por lo tanto, ambos fueron víctimas de una disputa acaso rancia, pues relegaron su calidad 
periodística y su capacidad de análisis a un diálogo monótono y agresivo que quizás haya sido interesante para sus alocutarios, pero no para los auditores de un espacio público que ya estaba dejando atrás, no sin dificultades, las prácticas facciosas relacionadas con la prensa.

\section{Referencias bibliográficas}

ALONSO, P. (2004): La Tribuna Nacional y Sud-América: tensiones ideológicas en la construcción de la "Argentina moderna" en la década de 1880. En: Construcciones impresas. Buenos Aires: Fondo de Cultura Económica.

BORRAT, H. (1989) El Periódico, Actor político. Barcelona, Gustavo Gilli.

BRAGONI, B.; MíGUEZ, E. (eds.) (2010) Un nuevo orden político. Provincias y estado nacional, 1852-1880. Buenos Aires: Biblos.

CAMPOBASSI, J. (1975) Sarmiento y su época. Tomo II Buenos Aires: Losada.

CHECA GODOY, A. (1993). Historia de la prensa en Iberoamérica. Sevilla: Alfar.

DE MARCO, M.A. (2006). Historia del periodismo argentino. Desde los orígenes hasta el Centenario de Mayo. Buenos Aires: Editorial de la Universidad Católica Argentina.

DÍAZ, C. L. (2012) Comunicación y Revolución. 1759-1810: esfera y espacio público rioplatense. Periodismo, censura, prácticas y ámbitos de lectura, La Plata: Ediciones de Periodismo y Comunicación.

DUCROT, O. (1986) El decir y lo dicho: polifonía de la enunciación. Madrid: Paidós Ibérica.

GALVÁN MORENO, C. (1944) Historia del periodismo argentino. Buenos Aires: Editorial Claridad.

HALPERÍN DONGHI, T. (1985). José Hernández y sus mundos. Buenos Aires: Editorial Sudamericana - Instituto Torcuato Di Tella (Colección Historia y Sociedad).

LETTIERI, A. (2008) La República de las instituciones. Buenos Aires: Editorial Prometeo.

MARTINI, S. (2000) Periodismo, noticia y noticiabilidad. Buenos Aires: Grupo Editorial Norma.

MOYANO, J (2008) Prensa, modernidad y transición. Buenos Aires: Editorial Universidad de Buenos Aires. 
-- (2015) Del estado al mercado: el periodismo mitrista en la modernización de la prensa argentina (1862-1904). En: Pineda, Adriana y Gantús, Fausta: Recorridos de la prensa moderna a la prensa actual. México, Universidad Michoacana de San Nicolás de Hidalgo, Red de Historiadores de la Prensa y el Periodismo en Iberoamérica y Universidad Autónoma de Querétaro. Pág. 55 a 89.

OJEDA, A. (2010) De la Arenga Faccional al Reclame Publicitario. Barcelona.En: revista Pensar la Publicidad, no 2.

PASTROMERLO, S. (2016) Sobre la modernización de los diarios en Buenos Aires. Avisos, noticias y literatura durante la guerra Franco-Prusiana 1870. En: Delgado, V. y Rogers, G. (eds.) Tiempos de Papel, Publicaciones periódicas argentinas (siglos XIX-XX). Facultad de Humanidades: Universidad de La Plata.

REBOLLO PAZ, L. (1968) Sarmiento Presidente. Buenos Aires, Talleres Gráficos.

RIVADENEIRA PRADA, R.I (1991) El periodismo: La teoría general de los sistemas y la ciencia de la comunicación. México, Trillas.

ROCCHI, F. (1999) Inventando la soberanía del consumidor: publicidad, privacidad y revolución del mercado en la Argentina, 1860-1940. En: Fernando Devoto y Marta Madero (eds.), Historia de la vida privada en la Argentina, Buenos Aires, Taurus-Alfaguara.

SABATO, H. (2012) Historia de la Argentina (1852-1890). Buenos Aires: Siglo veintiuno editores.

SIDICARO, R. (1993). La política mirada desde arriba: las ideas del diario La Nación (1909-1989). Buenos Aires: Sudamericana. 